\title{
Theoretical and Methodological Contributions of Narrative Psychology to Ethnic Identity Research
}

\author{
Moin Syed \\ University of Minnesota, Twin Cities
}

This is a post-print version of:

Syed, M. (2015). Theoretical and methodological contributions of narrative psychology to ethnic identity research. In C. Santos \& A. J. Umaña-Taylor (Eds.). Studying ethnic identity: Methodological advances and considerations for future research (pp. 27-54). Washington, DC: American Psychological Association.

Address correspondence to Moin Syed, moin@umn.edu 


\begin{abstract}
The purpose of this chapter is to showcase how narrative, or the stories that people tell about their experiences, is a useful theoretical and methodological tool for understanding ethnic identity development. Over the past two decades, research on ethnic identity development has primarily relied on quantitative, rating-scale instruments (Phinney, 1992; Sellers et al., 1998). While this methodology has contributed to a strong knowledge base regarding the correlates and developmental course of ethnic identity (Quintana, 2007), what has been lacking is an analysis of the lived experiences that constitute one's ethnic identity and contribute to its development. To this end, the chapter includes a synthesis of published and ongoing studies to illustrate how a narrative approach can contribute to theoretical issues of major importance to the study of ethnic identity: how ethnic identity develops, the role of context in development, and the dimensionality of ethnic identity. These examples highlight the close connection between method and theory, as well as how narrative research can inform subsequent survey-based work.
\end{abstract}

Keywords: Ethnic Identity, Narrative, Development 
Two decades of research on ethnic identity development has yielded some important findings (Quintana, 2007; Rivas-Drake, Seaton et al., in press). Recent meta-analyses indicated that ethnic identity is consistently, although modestly, associated with positive well-being, psychological distress, and academic attitudes (Rivas-Drake, Syed et al., in press; Smith \& Silva, 2011). Other research has suggested that ethnic identity contributes to the ability to cope with the harmful effects of discrimination (Yip, Gee, \& Takeuchi, 2008; but see Yoo \& Lee, 2008). In addition to gaining knowledge of the correlates of ethnic identity, we now also have a clearer picture of the longitudinal course of ethnic identity from early adolescence into emerging adulthood. Taken together, these studies suggest that ethnic identity waxes and wanes across school transitions, but generally increases over time (French, Seidman, Allen, \& Aber, 2006; Pahl \& Way, 2006; Syed \& Azmitia, 2009). Thus, it is safe to say that we have learned many things about ethnic identity development. But there are many things we do not know. For example, we know that change in ethnic identity occurs throughout adolescence and emerging adulthood, but we know little to nothing about why or how that change comes about.

In general, there has been a dearth of analyses focusing on the lived experiences that constitute one's ethnic identity and contribute to its development. The primary reason for this is that research on ethnic identity development has relied heavily on quantitative, rating-scale instruments (Phinney, 1992; Sellers, Smith, Shelton, Rowley, \& Chavous, 1998). These instruments are exceptionally valuable-indeed, they led to all of the discoveries that I listed at the outset. However, our ability to answer complex questions about the process, content, and structure of ethnic identity development has been constrained by a narrow methodological repertoire (Schwartz et al., in press).

The purpose of this chapter is to showcase how narrative, or the stories that people tell about their experiences, is a useful theoretical and methodological tool for understanding ethnic identity development. To do so, I will synthesize a series of published and ongoing studies on ethnic identity using narrative and survey approaches to demonstrate that the use of an alternative method has opened the door for deeper theorizing on the nature and consequences of ethnic identity development.

\section{Conceptualization of Ethnic Identity}

There are three primary conceptions of ethnic or racial identity represented in the psychological literature, each associated with a different psychological tradition: Phinney's (1990) developmental model, Sellers and colleagues' (1998) Multidimensional Model of Racial identity (MMRI; social psychology), and Cross’s (1971) Nigrescence theory (personality psychology). The work described in this chapter is situated within Phinney's developmental model of ethnic identity. This is the case for a very simple reason: I am a developmental psychologist, and Phinney's model is the only one that I consider developmental. The MMRI is a social psychological model, and as such does not include any theoretical propositions pertaining to change in its core dimensions (Syed, 2013). Although there are longitudinal studies using dimensions of the MMRI (e.g., Hughes, Way, \& Rivas-Drake, 2011), a longitudinal design is not a sufficient condition for a developmental perspective (Wohlwill, 1973). Nigrescence theory includes articulated mechanisms of change, but the proposed stage theory is idiosyncratic rather 
than age-graded. Additionally, there are no longitudinal studies demonstrating hypothesized movement through the stages. Finally, in the revised version of Nigrescence theory, Cross and colleagues have moved away from the stage aspect of the theory and recast the stages as "attitudes" that can be arranged in different configurations at any given time (Cross \& Cross, 2008).

As a developmental theory, Phinney’s has roots in Erikson’s (1950) lifespan psychosocial theory of development and, more directly, in Marcia’s (1966; Kroger \& Marcia, 2011) identity status model. Fundamentally, ethnic identity is viewed as an evolving developmental process that involves coordination of cognitive, affective, and behavioral dimensions of identification with an ethnic group: the cognitive dimension refers to the clarity and resolution of the meaning of ethnicity, the affective dimension is the emotional significance and pride associated with ethnicity, and the behavioral dimension is the degree to which individuals engage in a process of exploring and learning about their ethnicity. These three dimensions underlie the current measurement of ethnic identity from a developmental perspective, although not always in the same way. Some measures combine the affective and cognitive components into a single commitment dimension, complemented by an exploration dimension to capture the behavioral component (Phinney \& Ong, 2007; Roberts et al., 1999). Other measures retain the three dimensions as separate (Juang \& Nguyen, 2010; Lee \& Yoo, 2004; Umaña-Taylor, Yazedjian, \& Bámaca-Gómez, 2004). Regardless of the way in in which it is measured, under the developmental model, ethnic identity is presumed to have roots in childhood but emerges as a salient developmental task in early adolescence that continues into emerging adulthood and beyond (Umaña-Taylor et al., in press). Through a period of exploration, youth come to a sense of resolution about the role of ethnicity for their identities, whether it is positive or negative.

My own working conception of ethnic identity is heavily rooted in Phinney's model, but is more Eriksonian in nature. That is, many neo-Eriksonian researchers, Phinney included, take Marcia's identity status model as their starting point (see Schwartz, 2001). The identity status model relies on the processes of exploration and commitment to assign individuals to one of four identity statuses: achieved (high past exploration, high commitment), foreclosed (low past exploration, high commitment), moratorium (high current exploration, low commitment), and diffused (low exploration, low commitment). Within this model, diffusion and foreclosure are viewed as less mature identity statuses, and the developmental prerogative is for individuals to move to a period of moratorium and ultimately to achievement (Kroger \& Marcia, 2011). While this model has been used extensively, it has also been criticized as not being an accurate representation of Erikson's theorizing (Côté \& Levine, 2002).

In response, there is a recent movement within the identity field to go back to Erikson's original works to further refine theories of identity development (e.g., Hammack, 2008; McLean, Syed, Yoder, \& Greenhoot, 2013; Schachter, 2004; Syed, 2012b). The direction I have taken such efforts is to move away from the Marcian characterization of development as progression from foreclosure to achievement in favor of a characterization of development as an increasing sense of integration. This characterization is consistent with Erikson (1968), who described a healthy identity as one in which individuals integrate disparate aspects of the self (e.g., ethnic, gender) and integrate themselves through time (past, present, and future). 
Taking this approach has several benefits. First, it brings attention beyond the heavy focus on identity processes found in the literature. The process of identity development-how individuals arrived at where they are-has long been viewed as more important than the content of identities, what those identities actually look like (Syed \& Azmitia, 2010). In addition to process and content are identity structures, the configuration of relevant identities within a particular person (Schachter, 2004). Thus, ethnic identity — and identity more broadly—can be thought of as consisting of process, content, and structure (Hammack, 2008). Second, this approach allows room for heterogeneity in the identity process, content, and structure rather than mandating a particular developmental sequence (e.g., Phinney, 1993; Cross, 1971). Third, and most pertinent to the task at hand, locating my conceptualization of ethnic identity largely within an Eriksonian vs. neo-Eriksonian perspective permits flexibility in the types of research questions I pursue and the methods through which I pursue them. That is, the identity status model is rather limited in scope vis-à-vis the universe of the identity concept. Erikson has been accused of many things, but "limited in scope" is certainly not among them. In this chapter, I will highlight how narrative psychology helps to realize these benefits, focusing on (a) how ethnic identity develops, (b) the role of context in development, and (c) the dimensionality of ethnic identity. But first, we need to know about the narrative approach to identity.

\section{Overview of Narrative Approaches to Identity}

McAdams's (2001) autobiographical life-story model focuses on how individuals construct their identities through the process of creating and telling their life stories. McAdams argues that individuals' stories from the past are integrated into an evolving and internalized narrative identity. From this perspective, stories are not only representations of identity, but stories are the identity. That is, whether or not they are conscious of it, people see their lives in storied terms, viewing themselves as the authors of a life consisting of multiple chapters, highs and lows, turning points, heroes and villains, and various settings (McAdams, 2013). Moreover, the life story is constantly being written and revised, as past experiences are subject to reinterpretation to fit with individuals' current beliefs and goals for the future.

McAdams' model draws upon Eriksonian theory, and thus has strong developmental underpinnings. The life story does not begin to develop in earnest until adolescence, when youth develop advanced cognitive skills that allow them to reflect on their lives in sophisticated ways. These skills include the ability to recognize and reconcile contradictions in their beliefs and behaviors, to link different aspects of their lives in causal terms, and to achieve a sense of thematic coherence that unites disparate aspects of the self (Habermas \& Bluck, 2000; Harter \& Monsour, 1992). These cognitive advances facilitate adolescents' ability to make meaning of their past experiences, a key element of the narrative identity model. Meaning-making is defined as reflecting on past events to see how individuals have changed over time (McLean, Pasupathi, \& Pals, 2007). It serves as a core psychological process in connecting memories to identities, and therefore is a driving force for identity development (McLean, 2005; Thorne \& McLean, 2003; Thorne, 2000).

Within the narrative identity approach, the term "narrative" represents both the theory and the method. This is one of the major distinctions between narrative and other methods that rely on open-ended data. As described above, narrative is the theory, or more accurately the 
metaphor (Sarbin, 1986), that guides the approach to identity. Narrative also represents the method, as the data gathered in narrative studies are stories, or episodic memories from the past. Thus, rather than requesting participants to talk about how they think or how they feel about a particular topic, narrative studies request specific memories of events. Stories are a natural way for humans to communicate (Bruner, 1990), and therefore provide an easy and familiar way for individuals to discuss their experiences. Because all stories are filtered through individuals' current context, respondents indirectly and unknowingly reveal how they are thinking and what is important to them at that time. This approach has a long history in psychology, going back to Henry Murray (1938), the development of the Thematic Apperception Test, and the personological tradition (Hogan, 1976).

\section{Existing Research Highlighting the use of Narrative to Study Ethnic Identity}

Despite the promise, there has not been a whole lot of research using an explicitly narrative approach to study ethnic identity development, particularly from a psychological perspective. There are, however three strands of related work. First, there is some narrative research in education (Nasir \& Saxe, 2003), discourse studies (Malhi, Boon, \& Rogers, 2009), communication (Gudykunst, 2003), and cultural studies (Langellier, 2010), but they define ethnic identity in very different ways. Second, within psychology, there has been an increasing number of ethnic identity studies using qualitative methods, such as interviews (Rogers \& Way, this volume; Charmaraman \& Grossman, 2010), journaling (Vo-Jutabha, Dinh, McHale, \& Valsiner, 2009), ethnography (Ortiz et al., this volume), and participant observation (Way, Santos, Niwa, \& Kim-Gervey, 2008). None of these studies, however, are narrative per se, in that they are not informed by models of narrative identity and do not explicitly examine participants' stories. That is, while stories may be told in the course of the interviews or other open-ended data, stories tend not be directly requested, and the analytic approach is not narrative. Finally, there are many narrative studies of cultural identity (e.g., Gone, Miller, \& Rappaport, 1999; Hammack, 2006), which tend to focus on values, beliefs, and behaviors, rather than the subjective importance of one's cultural background. For example, Wang (2008) examined how Asian American participants' memories were influenced by a prime that made salient their Asian vs. American identities. The focus of the analysis was the degree to which the memories contained elements that were personal-focused or social-focused, consistent with the dichotomous independent-interdependent model of self-construal widespread in the crosscultural literature (Markus \& Kitayama, 2001).

There are, however, some studies that used a narrative approach to understand the psychological aspects of ethnic identity. In one of the first of those studies, Syed and Azmitia (2008) collected survey-based data on ethnic identity exploration and commitment using the multigroup ethnic identity measure (MEIM; Roberts et al., 1999) and narratives about ethnicityrelated experiences. Through an iterative and interactive process, the research team inductively generated a coding system that identified the main themes in the data (see Syed \& Azmitia, 2008, for more detail). The coding system resulted in four narrative themes that captured $95 \%$ of the stories: (a) experiences of prejudice, racism, discrimination, or oppression (experiences of prejudice stories); (b) feelings of connection, closeness, or belongingness to their ethnic and/or cultural background (connection to culture stories); (c) a time when they became aware that they were different ethnically, either from those in other ethnic groups or their own group (awareness 
of difference stories); and (d) a time that that they were in the numerical minority in a particular context (awareness of under-representation stories). Turning to the survey data, we then used cluster analysis, a person-centered statistical procedure, to create identity status categories based on participants' reported levels of exploration and commitment on the MEIM (see Phinney, 1993). This provided us with a content measure of ethnic identity (the narrative themes) and a process measure of ethnic identity (statuses) that could then be compared. The results indicated that those in the achieved status (high levels of exploration and commitment) were most likely to tell experience of prejudice or connection to culture stories, whereas those in the unexamined status (low levels of exploration and commitment) were more likely to tell awareness of difference and awareness of under-representation stories. In a subsequent longitudinal study (Syed \& Azmitia, 2010), we found that respondents who increased in ethnic identity exploration over 18 months were more likely to change their story theme, particularly to experience of prejudice or connection to culture. In contrast, those who decreased or remained stable were more likely to tell a story with a similar theme at both time points. Moreover, $18 \%$ of respondents told the same story at both time points, with all of those being participants who decreased or remained stable.

Taking these findings together suggests that a more developed ethnic identity is associated with a broader and more personalized repertoire of ethnicity-related experiences. For those who are actively engaged with their ethnic identities, the focus seems to be personal, and when asked to recount an ethnicity-related memory they select one of many available such memories. In contrast, individuals who are not actively involved with their ethnic identities seem to focus more on difference, and this focus is maintained across multiple requests for a memory. The personal experiences of prejudice and connections to culture are thus indicative of what it means to identify with one's ethnic background.

Thus, drawing upon a narrative model of identity, and integrating findings from narrative research with survey-based research, can lead to greater insights about ethnic identity development than we have seen with much of the extant research. I provide three examples in the next section of this chapter.

\section{Empirical Illustrations: Three Insights from Narratives}

In selecting the insights to describe in detail, I elected not to simply reiterate the findings from my published narrative research (Syed, 2010a, 2010b, 2012a; Syed \& Azmitia, 2008, 2010). The interested reader can consult those papers directly. Rather, I opted to highlight insights that I have gleaned through doing narrative research. The three insights described below speak to theoretical issues of major importance to the study of ethnic identity: (a) how ethnic identity develops, (b) the role of context in development, and (c) the dimensionality of ethnic identity. In describing these insights, I review studies that are based on both narratives and surveys, and report on some emerging findings from our unpublished work. The reason I am including survey work in a chapter on narrative methods is because I never would have thought to do the particular survey research that I discuss if not for my work with narratives. Thus, I highlight not only what can be learned through narrative research, but also how "narrative thinking” can inform subsequent survey-based work. 


\section{“Encounters,” “Triggers,” and “Turning Points”: All Misleading vis-à-vis Identity}

The words "encounters," "triggers," and "turning points” invoke similar imagery: Speed. Abrupt change. These words were not selected at random. "Encounter" is one of the stages in Cross' (1971) Nigrescence theory, and the term "trigger" has been used by Phinney and other researchers using her model (Pahl \& Way, 2006; Phinney \& Rosenthal, 1992; Quintana, 2007; Syed \& Azmitia, 2009; Yip, 2005). "Turning points" are frequently used in narrative research to designate memories that reflect a change or reorientation in how one views the self (McLean \& Pratt, 2006). These terms suggest that ethnic identity can change quickly as a result of some singular event or series of events; that one day, an individual who never thought much about his or her identity may have an experience (e.g., discrimination) and BAM! that person is set on a course to become strongly ethnically-identified.

To be fair, so far as I am aware no one actually believes that. However, it is important that these heavily-used terms suggest it, and such a suggestion has real impact both theory and research. Conceptualizing time is a major task of the developmental scientist (Wohlwill, 1973), and the manner in which we do so can affect our interpretations of how time plays a role in psychological phenomena (Lerner, Schwartz, \& Phelps, 2009). Thus, it seems important that we take a closer look at these dominant speed metaphors, and how well they fit with how ethnic identity actually develops.

The findings from narrative studies suggest that the abrupt change suggested by "encounter" and "trigger" is unlikely to be a frequent experience. I will provide two examples using different methodological approaches. These examples make use of the narrative concept of meaning, or reflecting on past events and connecting them to self. When we examine the meaning-making process in detail, a different picture of the speed of identity development begins to emerge.

When recounting stories of their past experience, individuals talk about both "what happened" at the time of the event itself (from their current perspective, of course), as well as how they think about that event at the time of the telling. Thus, an element of time is embedded within the stories. We recently began work on understanding this construction of time in narratives by separating stories into immediate (at the time of the event) and delayed (after the event itself) components (Walker \& Syed, 2011). We then coded these segments for the presence of markers that indicate affective (emotions), behavioral (did they “do" anything?), and cognitive (meaning-making) processes, as these have been identified as the three broad domains of ethnic identity (Ashmore, Deaux, \& McLaughlin-Volpe, 2004; Phinney, 1993). This resulted in a "deconstructed" narrative in which we create a 2 (time) X 3 (dimension) matrix to represent the stories. While affective and behavioral components were most frequently located in the immediate events, the cognitive component—-meaning-making — was much more likely to occur in the delayed segment. This finding indicates that meaning-making is not occurring immediately following an event, as would be suggested by "encounter" and "trigger." Rather, meaningmaking takes place after a period of time in which individuals have had time to think about the experience, talk to others, or have subsequent experiences that led them to re-think the original event (McLean et al., 2007; Thorne, 2000). 
A limitation of the above study —and the vast majority of narrative research—is that is it cross-sectional and retrospective. What we need are longitudinal studies of meaning-making, wherein individuals talk about the same event both when it is relatively recent and after a period of time. In other words, the study needs to be both prospective and retrospective. Such studies are hard to come by, but there is one that is useful to consider. This study was not about ethnic identity development, per se, but rather was about how college students integrate their ethnic and academic identities over time (Syed, 2010a). One particular case is germane to the current topic. During her sophomore year, a student discussed participating in an ethnic-based educational activity. At that time, she described it as fun and interesting, but not much more. When we spoke to her in her senior year of college, she targeted that experience as a "turning point" for her identity. That may very well be the case, but that is not the way she viewed it at the time. Retrospectively, however, that singular experience has been identified as the primary source of identity change. It may have been a turning point, but she did not know that when it was happening. It is likely quite rare for individuals to be conscious of their own identity-related turning points. On the occasions when they are, it may be best referred to as an epiphany (see Cross \& Cross, 2008).

In sum, narrative research suggests that identity is generally a slow process that unfolds over time (see also Josselson, 2009). Moreover, notions of abrupt identity change are likely to be a product of retrospective construction of past experiences, rather than the way in which identities actually change in response to life experiences. Thus, there is a distinction between how identities change and how we construct and situate those changes within our life stories.

\section{Social Context: Cold and Hot}

A small wave of research several years ago began to investigate the degree to which ethnic density, or the relative proportion of co-ethnics in a given geographical area, may be associated with ethnic identity development (Juang, Nguyen, \& Lin, 2006; Syed, Azmitia, \& Phinney, 2007; Umaña-Taylor, 2004). On the one hand, Eriksonian identity theory, which stresses the importance of resources and opportunities from which individuals can draw upon their identities, suggests that individuals in contexts with high ethnic representation should have stronger and more fully developed ethnic identities. Social identity theory, on the other hand, specifies that group identification is heightened and subsequently strengthened when that group is in the minority (Tajfel \& Turner, 1986). Thus, from this perspective, it is contexts with very low representation that should give rise to stronger ethnic identities.

The findings on the role of ethnic density reflect these theoretical contradictions, sometimes finding differences in levels of ethnic identity but not links to mental health (UmañaTaylor, 2004), differences in links to mental health but not in levels (Juang et al., 2006), and no differences in levels or developmental trajectories (Syed et al., 2007). Thus, the role of social context—as defined by ethnic density—-for ethnic identity development is far from clear.

At the 2008 Society for Research on Adolescence meeting, Andrew Fuligni served as a discussant for a symposium on ethnic identity process and content. In his comments, he drew upon the distinction between cold cognition and hot cognition (Abelson, 1979). Cold cognition refers to basic information processing, such as learning and memory. Hot cognition, however, 
refers to how those cognitive processes are influenced by the emotional and motivational contexts in which they are performed. Fuligni made a connection between the cold/hot cognition distinction and the way in which contexts are conceptualized in ethnic identity research. He suggested that ethnic density is “cold context” because it relies purely on the relative proportion or representation of a particular group in a particular geographical area (typically ill-defined; see Syed \& Juan, 2012). The context can be understood through looking up the appropriate figures on the U.S. Census website. What is lacking in this approach is how individuals personally experience these social contexts, which is the core idea of "hot context." I have frequently made a similar distinction between objective (e.g., density) and subjective contexts (Syed, 2010a; Syed \& Juan, 2012; see also Juang \& Alvarez, 2011; Way et al., 2008). Past research indicates that the same "context" is not perceived similarly for different individuals who are a part of it (Syed, 2010a). That is, the same level of density in the same geographical location can be viewed as "diverse” by one individual and "not very diverse” by another. Although research directly comparing the two is minimal, the existing research suggests that subjective assessments of context have more predictive power than objective assessments (Juang \& Alvarez, 2011; Syed \& Juan, 2012; Yip, Seaton, \& Sellers, 2010; Way et al., 2008).

Bringing awareness of this distinction to ethnic identity scholars paves the way for asking new questions about how contexts matter for ethnic identity development. Way et al. (2008) provide a useful example of this point through their ethnographic study of ethnic identity of Puerto Rican, Dominican, Chinese American, and African American high school students. The Chinese American students were well-represented in the schools (cold context) but were at the bottom of the peer social hierarchy (hot context). In contrast, the Puerto Rican students were fewer in number but enjoyed the highest social status. Through their interviews and observations, Way et al. determined that the peer social context played a much bigger role in the students' ethnic identity experiences than did their raw numerical representation. Thus, rather than focusing on "how many," a greater consideration of the hot context allows for questions about how individuals directly engage with their contexts, both actively and passively. Narratives may have some advantages relative to rating-scale surveys for addressing these questions. I provide two empirical examples below.

In addition to contributing to an understanding of development, narrative meaningmaking may be one route for assessing the hot context of ethnic identity. Two types of stories that repeatedly appear in my narrative studies are awareness of difference stories and awareness of under-representation stories (Syed \& Azmitia, 2008, 2010; Walker \& Syed, 2011). Awareness of difference stories are about times in which individuals become aware that they are ethnically different from others. There is an inherent element of meaning-making, as the teller often observed something (e.g., different food practices) and subsequently gained some insights about their ethnic identity (e.g., the food of my culture is considered "weird" by others). In contrast, awareness of under-representation stories are commentaries on the relative diversity in a particular context (e.g., I went to a party, looked around, and saw that I was the only Asian guy there). No meaning is made of the experience, it is simply a story about a time the teller realized that he or she was in the minority (or in some cases majority), and is thus an example of cold ethnic context. An important-and still yet unanswered-question is why do some individuals attach meaning to the experience and others not? Both types of stories are related to lower levels of ethnic identity, assessed via survey measures. It is possible, however, that the awareness of 
difference stories are told by individuals who are primed for development. They may not have thought much about their ethnicities, but they are beginning to, and thus have thought enough about their experiences to imbue them with meaning. These two story types, largely differentiated by meaning, show how individuals differently engage with their cold contexts. Knowing simply that they were in a situation where they noticed a difference may not be as useful for understanding ethnic identity as knowing the meaning they made about the difference.

Another way to think about the hot context of ethnic identity is how individuals talk about race and ethnicity with others. The dominant focus in the literature in this regard is research on racial and cultural socialization (Hughes et al., 2006). Racial socialization is the process through which individuals convey messages about the role and meaning of race in society. One form of racial socialization is preparation for bias, where individuals communicate the potential for institutional and personal racism and discrimination. In contrast, cultural socialization is the process through which individuals are exposed to the history, traditions, and practices associated with their ethnic or cultural group (Umaña-Taylor, 2001). Both racial and cultural socialization have been positively linked to ethnic identity (Hughes et al., 2006). The majority of the literature has relied on rating-scale instruments and has identified parents as the primary socialization agents. One narrative study, however, suggests a more dynamic view of socialization.

In a recent study, I had college students first write down an ethnicity-related memory, then write down a memory about telling that memory to someone else (Syed, 2012a). This is referred to as a telling memory — a memory about telling a memory (Thorne \& McLean, 2003; McLean, 2005). First of all, only $60 \%$ of the stories had been told to others at all; the remaining $40 \%$ had never been told. Of the stories that were reported to have been told, I analyzed the data for what the story was about and who they told it to. One of the key findings is that stories about discrimination were most likely to be told to peers, whereas stories about learning about one's cultural background were most likely to be told to parents. This distinction in story content aligns with the distinction between racial socialization and cultural socialization, respectively, and suggests that peers may be important agents of racial socialization whereas parents may be important agents of cultural socialization. This "division of labor" regarding socialization had not been previously recognized or discussed, in part because peer ethnic socialization has scantly been investigated in past research. These findings led me to do just that, assessing both racial and cultural socialization from peers and parents using rating scale instruments (Syed \& Hu, 2013). The results dovetailed with the narrative observations: greater ethnic identity exploration and commitment were associated with higher levels of parental cultural socialization and higher levels of peer preparation for bias (Figure 1). Thus, this example illustrates how by understanding the ways individuals interact with their contexts-to whom they tell different life experiences - we can develop new empirical and theoretical ideas about how identities are managed and the specific sources of their development.

\section{Exploration is Not Exploration is Not Exploration}

Ethnic identity exploration is a critical component of ethnic identity development (Phinney, 1990). Exploration has traditionally been conceptualized as a unidimensional construct. My narrative research, however, made it clear to me that there are likely different 
ways of "doing" exploration. This observation dovetails with the relatively low alpha for the MEIM exploration scale (in comparison with the MEIM commitment scale). Someone might talk to others about ethnicity, for example, but that does not necessarily mean that they will attend ethnicity-related events. Thus, there is some evidence that ethnic identity exploration may be a multidimensional construct.

My final illustration is a more direct example of how narrative research can contribute to more traditional forms of ethnic identity research. Conducting narrative research is not for everyone, but such research should not be considered as a "separate stream" from research based on survey measures. My narrative work is what motivated me to think of exploration as a multidimensional process; that there may be distinct forms of exploration with which individuals engage. I then returned to survey data to examine whether ethnic identity exploration, as currently measured with rating-scales, has multiple sub dimensions. Along with several of my colleagues, I used the MUSIC data set (an online survey of over 10,000 college students from across the U.S.; see Weisskirch, et al., 2013, for detailed description of method and sample), which has both a very large number of ethnic minority participants $(\mathrm{N}>3,000)$ and contains the two leading measures of ethnic identity exploration, the MEIM and the EIS (Ethnic Identity Scale; Umaña-Taylor et al., 2004). We factor analyzed the two scales together to test whether exploration made up a single latent factor or could be conceptualized as multidimensional. The results were rather striking (Syed et al., 2013).

As I suspected, there were multiple factors, but not exactly in the way I had imagined. Each scale, in fact, constituted its own factor. This could be dismissed as due to method factors, but that does not appear to be the case. Close inspection of the items from each scale suggests that they may actually be tapping into different exploratory processes and outcomes. The EIS items pertain to concrete behaviors in which the individuals learned something about their identities ("participation'). The MEIM items, on the other hand, generally tap into exploratory processes that have less clear of an outcome ("search"). That is, those items about talking to people, attending events, and readings books, do not explicitly state that anything was learned. It becomes clear that these two scales are tapping into different forms of exploration when using them as simultaneous predictors of well-being. Participation (via the EIS) positively predicted higher well-being, whereas search (via the MEIM) negatively predicted well-being. Note that the zero-order correlation between the MEIM exploration scale and well-being is zero. Thus, the potentially negative impact of search-related exploration is being suppressed until the positive impact of participation is removed. Search on its own is not a bad thing, but search outside of participation appears to be negative. Further models we tested revealed why this is the case: participation leads to identity coherence, which leads to higher well-being. In contrast, search leads to identity confusion, which leads to lower well-being (see Syed et al., 2013).

The point of this example is to illustrate that my narrative research led to this analysis. Reading and analyzing individuals' stories about their ethnicity-related experiences broadened my thinking about constructs such as exploration and commitment. I was then able to cycle back and bring this new thinking to analyses based on rating-scale instruments. Indeed, this new lens allowed me to interpret and synthesize the existing research in new ways, and detect patterns of relations that I had not previously noticed (see Syed et al., 2013 for more details). The result is a deepening of ethnic identity theory; that there are (potentially) many ways that individuals "do" 
exploration, and these different ways may have different implications for psychological functioning. These findings open the door to new lines of inquiry in ethnic identity research. How many different types of exploration are there? What are their implications? Why do individuals engage in some rather than others? Is there a normative developmental pattern? At this time, these questions have no answers. Nevertheless, we should feel good about the fact that we are asking them.

\section{Strengths of using a Narrative Approach to study Ethnic Identity}

While I believe there are numerous strengths to using a narrative approach in the study of ethnic identity, I highlight just two of those strengths here. First, as I hope I have illustrated in the preceding, a narrative approach can lead to new insights that may be very difficult to achieve-impossible even — using rating-scale instruments. For new insights and discovery, it is hard to argue against the value of listening to and reading about individuals' everyday life experiences (Arnett, 2005; Charmaz, 2003; Thorne, 2000). This is particularly true for underrepresented and marginalized groups. Indeed, narrative figures prominently within the field of critical race theory as it gives voice to individuals who are largely silenced within the mainstream culture (see Duncan, 2005). Relying solely on rating-scale instruments-particularly those that have not been subject to psychometric rigor (e.g., the multi-trait multi-method matrix, Campbell \& Fiske, 1959; invariance testing, Knight, Roosa, \& Umaña-Taylor, 2009)—could result in overlooking constructs or dimensions that are important to the group of interest.

The second strength of the narrative approach to ethnic identity is that it allows individuals to specify their own context. That is, through telling their stories, individuals communicate what is important about themselves and their surrounding environment. Not only do you often get information about where they were, who they were with, and what they were doing, but also information about their subjective evaluation of the situation. On a related note, narratives can often reveal links across different life domains or areas of functioning, even if you were not looking for them. In some of our work on identity development more broadly, we have begun to examine the degree to which domains of identity tend to co-occur within a single narrative, and whether certain identity domains surface when respondents are recounting stories about different domains (McLean et al., 2013). If asked for a memory about politics, do they also tend to weave in discussions of values and occupation? This work is ongoing, so as yet we do not have definitive answers. These are the kinds of questions, however, that narratives are wellpositioned to address.

\section{Challenges of using a Narrative Approach to study Ethnic Identity}

Despite the strengths associated with adopting a narrative approach to the study of ethnic identity, there are, of course, some challenges as well. Here I review some of the conceptual challenges. The more procedural challenges are discussed in the subsequent section on best practices in narrative research. Many researchers who study ethnic identity do so because they believe it has relevance to the psychosocial functioning of ethnic minority youth (see Quintana, 2007). Accordingly, many studies seek to connect dimensions of ethnic identity to important indicators such as well-being, distress, and academic functioning (see Rivas-Drake, Seaton et al., in press; Rivas-Drake, Syed et al., in press). This goal, in general, will be more easily 
accomplished using survey-based approaches than narrative approaches for three reasons. First, using narrative elements to predict psychosocial outcomes means that shared survey method variance will be removed from the analysis, as most psychosocial outcomes are measured via survey. Given that the effect sizes are small to moderate when this shared variance is present (Rivas-Drake, Syed et al., in press; Smith \& Silva, 2011), the reduction of method variance will likely attenuate effect sizes to triviality.

Second, narrative research is sometimes based on a single memory at a time (e.g., Syed \& Azmitia, 2008, 2010). It may be asking quite a lot to expect elements of a single memory to be associated with more generalized ratings of psychosocial functioning. Indeed, narrative research has the potential to be heavily affected by demand characteristics, as a number of situational and life factors could influence the memory that comes to mind in the lab. For this reason, narrative research outside of ethnic identity tends to collect several memories at a time from participants, typically between 3 and 10, which could either be of the same type (e.g., self-defining memories; McLean, 2005) or a variety of types (e.g., low point, high point, turning point, etc.; McAdams et al., 2006). Collecting numerous memories allows for the extraction of consistent elements that cut across individual memories, and thus provides insights into reminiscing that is more dispositional than situational. Such an approach may be more fruitful when looking for links to psychosocial functioning. Thus, depending on the research question, collecting a single narrative may not yield sufficient data. It is critical that the number and types of narratives requested appropriately match the goals of the research.

Finally, in narrative research you have little control over the nature of the responses. This is due to the fact that the "questions" asked in narrative research are for types of memories that can range in specificity. A typical prompt that I use is, "please describe an experience, either positive or negative, in which you became particularly aware of your race/ethnicity." This prompt is very open-ended, and can lead to a wide variety of memory types. This can be a good thing or a bad thing, depending on the research question. For example, at first glance such a prompt may not seem advantageous if a researcher was specifically interested in experiences of discrimination, as the prompt requested an experience in which the participants 'became aware' of their ethnicity and did not explicitly request a discrimination story. However, this prompt may actually yield stronger data by paradoxically generating a greater number of discrimination stories compared with a prompt that specifically requests an experience of discrimination. When describing experiences of discrimination, many participants do not use the words racism, discrimination, prejudice, or any other similar terms, and it is very likely that many of them would not readily label their experience of discrimination as such (see Syed \& Azmitia, 2008). Thus, directly requesting stories about discrimination could actually lead to lower rates of telling such stories. This suggestion is supported by past research. For example, when Pituc, Syed, and Lee (2010) specifically requested a memory about discrimination, over half of the participants responded that they had never had such an experience. Pasupathi, Wainryb, and Twali (2012) requested a memory of "a time when you felt singled out or treated differently, in a negative way, because of your ethnicity.” (p. 59). They did not use the word discrimination in their prompt, and yet still had 30\% of the sample state they had never experienced discrimination. Juang and Syed (2013) used the prompt, "please describe a time when you were a child or teenager when you felt treated differently because of your racial/ethnic/cultural background," and had only 14\% of the sample report not having such an experience. While similar to the Pasupathi et al. prompt, the 
Juang and Syed prompt did not include any valence, which could potentially have accounted for the greater compliance. The bottom line is one of great simplicity and immense importance: the way the question is phrased will impact the nature of the responses.

\section{Best Practices in Narrative Research}

When discussing narrative research with my more quantitatively-oriented colleagues I get a very consistent response: they think it is fascinating and relevant to what they do, but they have no idea how to do it. In this section, I briefly sketch a road map of crucial steps in the process of executing a narrative study, and offer some best practices for going about the work. This is by no means an exhaustive list of concerns, and the depth of the exposition will not be sufficient for someone interested in planning a study. Rather, this section should be viewed as a starting point from which further education and training can be pursued.

As with any qualitative-based methodology, narrative research requires a great investment of time and resources. Time and resources play a factor at several levels: collecting the data, transcribing the data (if necessary), developing the coding system, training coders, and coding the data. Potential pitfalls lurk at every phase of the project, which can lead to serious delays. I briefly discuss each of these phases, in turn.

Collecting the data. As with any study, considerations for data collection in narrative studies depend on the particular research question and study design. First, under no circumstances should a narrative study be launched without first conducting a pilot study. It is critical to test out the memory prompt(s) being considered to ensure that participants are responding to them as intended. In terms of sample size, narrative studies range from single-case studies (Schachter, 2005) to studies of several hundred participants (McLean \& Pratt, 2006), with the optimal choice being dependent on the goals of the research. Participants can communicate their stories by writing them down on paper, typing them on the computer, or telling them orally in interviews. The selection of the method should be done carefully, and is dependent on the research question and the types of memories being requested. For example, asking about especially sensitive memories that are resistant to disclosure (e.g., discrimination) may be best requested via hand writing or typing rather than interviews. The benefit of privacy, however, must be considered in relation to the limitation of being unable to ask follow-up questions. Regardless of the method through which the stories are told, narrative data must be collected in the research lab or other monitored setting in order to get high-quality data. In other words, the use of online surveys that participants complete on their own time should not be used for narrative research.

Transcribing the data. Creating verbatim transcripts is necessary for verbal and handwritten narratives. The formal transcripts become the data that are used for subsequent coding. Transcription takes an enormous amount of time-much longer than most people would think. A one hour interview does not take one hour to transcribe. A rough guide for transcribing one-on-one interviews is that every hour of interview will take approximately four hours to transcribe. The task can be facilitated by the use of transcription software and enlisting the services of experienced transcribers and/or skilled typists. Of course, having participants write their narratives on the computer obviates the need for this particularly onerous task. 
Developing the coding system. Collecting and transcribing the data are significant challenges, but developing the coding system can be the most daunting step in the process of narrative analysis. There are three broad approaches to developing a coding system, which range from the least to the most time intensive: (a) using an existing coding system, (b) modifying an existing coding system, and (c) creating a new coding system. I am frequently asked how many coding categories there should be within an optimal system. The answer: not too many, and not too few. More specifically, overly-detailed coding systems will likely result in losing focus of the big picture and will make it difficult to achieve acceptable inter-rater reliability (see below). Having too few categories will result in coarse categories that contain too much variability to be meaningful. The optimal system balances these two poles, and the precise number will depend on the research question. That said, a survey of the narrative identity literature would show that most coding systems tend to have between three and seven categories.

Training coders and coding the data. Once the coding system has been developed, coders need to be trained to follow the specified coding manual. Coders often consist of a mixture of research assistants (undergraduate or graduate students) and key personnel. The coders must go through a training period until they are able to achieve an acceptable level of inter-rater reliability. There are many different ways of establishing some type of reliability, ranging from qualitative, discussion-based methods such as the Listening Guide (Taylor, Gilligan, \& Sullivan, 1996) to quantitative methods such as percent agreement and Cohen's kappa (Bakeman \& Gottman, 1986). Regardless of the method, there should be some evidence that multiple perspectives were brought to bear on the narratives, both for the purpose of establishing reliability and also because differing views can lead to new insights that would not otherwise have occurred (see Taylor et al., 1996).

All of the phases described above involve substantial time, but they also require extensive training. This is not only the case for research assistants who often do the coding, but for the principal investigator as well. This barrier points to the increased need for graduate training in diverse methods as well as collaborations among researchers with varying skills. As narrative analysis is becoming increasingly prevalent within identity studies, there are greater opportunities for collaborations between narrative and non-narratives researchers. Only good things can come from such collaborations.

\section{Concluding Thoughts}

Ethnic identity has emerged as a major topic of study in developmental psychology and related fields. This emergence has come on the backs of a small number of rating-scale instruments that have seen widespread use. Now that much of the fundamental research on ethnic identity has been conducted, it will be critical to move beyond a sole focus on rating-scales of ethnic identity process and content. To contribute to further theoretical development, the study of ethnic identity must include diverse methodologies, including — but not limited to—narrative. My goal in this chapter was to make this point evident. Indeed, I hope to have demonstrated how methodological innovations can contribute to a deepening and refining of ethnic identity theory, and how a continued emphasis on method and theory is critical for advances in this important domain of positive ethnic minority development. 


\section{References}

Abelson, R. P. (1979). Differences between belief and knowledge systems. Cognitive Science, 3(4), 355-366.

Arnett, J. J. (2005). The vitality criterion: A new standard of publication for.Journal of Adolescent Research. Journal of Adolescent Research, 20, 3-7.

Ashmore, R. D., Deaux, K., \& McLaughlin-Volpe, T. (2004). An organizing framework for collective identity: Articulation and significance of multidimensionality. Psychological Bulletin, 130(1), 80-114.

Bakeman, R., \& Gottman, J. M. (1986). Observing interaction: An introduction to sequential analysis. Cambridge: Cambridge University Press.

Bruner, J. S. (1990). Acts of meaning. Cambridge, MA: Harvard University Press.

Campbell, D. T., \& Fiske, D. W. (1959). Convergent and discriminant validation by the multitrait, multi-method matrix. Psychological Bulletin, 56, 81-105.

Charmaraman, L. \& Grossman, J. M. (2010). Importance of race and ethnicity: An exploration of Asian, Black, Latino, and Multiracial adolescent identity. Cultural Diversity and Ethnic Minority Psychology, 16, 144-151

Charmaz, K. (2006). Constructing grounded theory: A practical guide through qualitative analysis. Pine Forge Press.

Côté, J. E., \& Levine, C. G. (2002). Identity, formation, agency, and culture: A social psychological synthesis. Psychology Press.

Cross, W.E. (1971). The Negro to Black conversation experience: Toward a psychology of Black liberation. Black World, 20,(5), 13-27.

Cross, W. E., \& Cross, T. B. (2008). Theory, research, and models. In S. M. Quintana \& C. McKown (Eds.), Handbook of race, racism, and the developing child, 154-181.

Duncan, G. A. (2005). Critical race ethnography in education: Narrative, inequality, and the problem of epistemology. In A. D. Dixson \& C. K. Rousseau (Eds.), Critical race theory in education (pp. 191-211). New York: Routledge.

Erikson, E. H. (1950). Childhood and society. New York: W W Norton \& Co.

Erikson, E. H. (1968). Identity: Youth and crisis. New York: Norton.

French, S. E., Seidman, E., Allen, L., \& Aber, J. L. (2006). The development of ethnic identity during adolescence. Developmental Psychology, 42, 1-10.

Gone, J. P., Miller, P. J., \& Rappaport, J. (1999). Conceptual self as normatively oriented: The suitability of past personal narrative for the study of cultural identity. Culture \& Psychology, 5(4), 371-398.

Gudykunst, W. B. (Ed.). (2003). Cross-cultural and intercultural communication. Sage.

Habermas, T., \& Bluck, S. (2000). Getting a life: The emergence of the life story in adolescence. Psychological Bulletin, 126, 248-269.

Hammack, P. L. (2006). Identity, conflict, and coexistence: Life stories of Israeli and Palestinian adolescents. Journal of Adolescent Research, 21(4), 323-369.

Hammack, P. L. (2008). Narrative and the cultural psychology of identity. Personality and Social Psychology Review, 12(3), 222-247.

Harter, S., \& Monsour, A. (1992). Developmental analysis of conflict caused by opposing attributed in the adolescent self-portrait. Developmental Psychology, 28(2), 251-260.

Hogan, R. (1976). Personality theory: The personological tradition. Oxford, England: PrenticeHall. 
Hughes, D., Rodriguez, J., Smith, E. P., Johnson, D. J., Stevenson, H. C., \& Spicer, P. (2006). Parents' ethnic-racial socialization practices: a review of research and directions for future study. Developmental psychology, 42(5), 747.

Hughes, D., Way, N., \& Rivas-Drake, D. (2011). Stability and change in private and public ethnic regard among African American, Puerto Rican, Dominican, and Chinese American urban early adolescents. Journal of Research on Adolescence, 21, 861-870.

Josselson, R. (2009). The present of the past: Dialogues with memory over time. Journal of Personality, 77(3), 647-668.

Juang, L. P., \& Alvarez, A. N. (2011). Family, school, and neighborhood: Links to Chinese American adolescent perceptions of racial/ethnic discrimination. Asian American Journal of Psychology, 2(1), 1-12.

Juang, L. P., \& Nguyen, H. H. (2010). Ethnic identity among Chinese-American youth: The role of family obligation and community factors on ethnic engagement, clarity, and pride. Identity: An International Journal of Theory and Research, 10(1), 20-38.

Juang, L. P., Nguyen, H. H., \& Lin, Y. (2006). The ethnic identity, other-group attitudes, and psychosocial functioning of Asian American emerging adults from two contexts. Journal of Adolescent Research, 21(5), 542-568.

Juang, L. P., \& Syed, M. (2013). Sharing stories of discrimination with parents. Manuscript under review.

Knight, G. P., Roosa, M. W., \& Umaña-Taylor, A. J. (2009b). Methodological challenges in studying ethnic minority or economically disadvantaged populations. Washington, DC: American Psychological Association.

Kroger, J., \& Marcia, J. E. (2011). The identity statuses: Origins, meanings, and interpretations. In S. J. Schwartz, K. Luyckx, \& V. L. Vignoles (Eds.), Handbook of identity theory and research (pp. 31-53). New York: Springer.

Langellier, K. M. (2010). Performing Somali identity in the diaspora: 'Wherever I go I know who I am'. Cultural Studies, 24(1), 66-94.

Lee, R. M., \& Yoo, H. C. (2004). Structure and measurement of ethnic identity for Asian American college students. Journal of Counseling Psychology, 51(2), 263-269.

Lerner, R. M., Schwartz, S. J., \& Phelps, E. (2009). Problematics of time and timing in the longitudinal study of human development: Theoretical and methodological issues. Human Development, 52, 44-68.

Malhi, R. L., Boon, S. D., \& Rogers, T. B. (2009). ‘Being Canadian’ and ‘Being Indian’: Subject Positions and Discourses Used in South Asian-Canadian Women's Talk about Ethnic Identity. Culture \& Psychology, 15(2), 255-283.

Marcia, J. E. (1966). Development and validation of ego identity status. Journal of Personality and Social Psychology, 3, 551-558.

Markus, H. R., \& Kitayama, S. (1991). Culture and the self: Implications for cognition, emotion, and motivation. Psychological Review, 98(2), 224-253.

McAdams, D. P. (2001). The psychology of life stories. Review of General Psychology, 5(2), 100-122.

McAdams, D. P., Bauer, J. J., Sakaeda, A. R., Anyidoho, N. A., Machado, M. A., \& MagrinoFailla, K. et al. (2006). Continuity and change in the life story: A longitudinal study of autobiographical memories in emerging adulthood. Journal of Personality, 74(5), 13711400.

McLean, K. C. (2005). Late Adolescent Identity Development: Narrative Meaning-making and 
Memory Telling. Developmental Psychology, 41, 683-691.

McLean, K. C., Pasupathi, M., Pals, J. P. (2007). Selves creating stories creating selves: A process model of self-development. Personality and Social Psychology Review, 11, 262280.

McLean, K. C., \& Pratt, M. W. (2006). Life’s little (and big) lessons: Identity statuses and meaning-making in the turning point narratives of emerging adults. Developmental Psychology, 42(4), 714-722.

McLean, K. C., Syed, M., Yoder, A., \& Greenhoot, A. (2013). The role of domain content in understanding identity development processes. Manuscript under review.

Murray, H. A. (1938). Explorations in personality.

Nasir, N. S., \& Saxe, G. B. (2003). Ethnic and academic identities: A cultural practice perspective on emerging tensions and their management in the lives of minority students. Educational Researcher, 32(5), 14-18.

Pahl, K., \& Way, N. (2006). Longitudinal trajectories of ethnic identity among urban Black and Latino adolescents. Child Development, 77(5), 1403-1415.

Pasupathi, M., Wainryb, C., \& Twali, M. (2012). Relations between narrative construction of ethnicity-based discrimination and ethnic identity exploration and pride. Identity, 12, 5373.

Phinney, J. S. (1990). Ethnic identity in adolescents and adults: A review of research. Psychological Bulletin, 108, 499-514.

Phinney, J. S. (1992). The multigroup ethnic identity measure: A new scale for use with diverse groups. Journal of Adolescent Research, 7(2), 156-176.

Phinney, J. S. (1993). A three-stage model of ethnic identity in adolescence. In M. E. Bernal \& G. P. Knight (Eds.), Ethnic identity: Formation and transmission among Hispanics and other minorities (pp. 61-79). Hillsdale, NJ: Erlbaum.

Phinney, J. S., \& Ong, A. D. (2007). Conceptualization and measurement of ethnic identity: Current status and future directions. Journal of Counseling Psychology, 54(3), 271-281.

Phinney, J. S., \& Rosenthal, D. A. (1992). Ethnic identity in adolescence: Process, context, and outcome. In G. R. Adams, T. P., Gullotta, \& R. Montemayor (Eds.), Adolescent identity formation. Advances in adolescent development, Vol. 4., (pp. 145-172). Thousand Oaks, CA: Sage Publications

Pituc, S. T., Syed, M., \& Lee, R. M. (2010, March). A mixed-method approach to illustrating the racial triangulation of discrimination. Paper presented at the biennial meeting of the Society for Research on Adolescence, Philadelphia, PA.

Quintana, S. M. (2007). Racial and ethnic identity: Developmental perspectives and research. Journal of Counseling Psychology, 54(3), 259-270.

Rivas-Drake, D., Seaton, E., Markstrom, C., Schwartz, S. J., Umaña-Taylor, A. J., French, S., Syed, M., Yip, T., Lee, R. M., \& Ethnic/Racial Identity Study Group (in press). Ethnic and racial identity in childhood and adolescence: Implications for psychosocial, academic and health outcomes. Child Development.

Rivas-Drake, D., Syed, M., Umaña-Taylor, A. J., Markstrom, C., French, S., Schwartz, S. J., Lee, R. M., \& Ethnic/Racial Identity Study Group. (in press). Feeling good, happy, and proud: A meta-analysis of positive ethnic-racial affect and adjustment among diverse children and adolescents. Child Development. 
Roberts, R. E., Phinney, J. S., Masse, L. C., Chen, Y. R., Roberts, C. R., \& Romero, A. (1999). The structure of ethnic identity of young adolescents from diverse ethnocultural groups. Journal of Early Adolescence, 19(3), 301-322.

Sarbin, T. R. (1986). The narrative as a root metaphor for psychology. In T. R. Sarbin (Ed.), Narrative psychology: The storied nature of human conduct, (pp. 3-21). Westport, CT: Praeger Publishers.

Schachter, E. P. (2004). Identity configurations: A new perspective on identity formation in contemporary society. Journal of Personality, 72(1), 167-199.

Schachter, E. P. (2005). Context and identity formation: A theoretical analysis and a case study. Journal of Adolescent Research, 20(3), 375-395.

Schwartz, S. J. (2001). The evolution of Eriksonian and neo-Eriksonian identity theory and research: A review and integration. Identity: An International Journal of Theory and Research, 1, 7-58.

Schwartz, S. J., Syed, M., Yip, T., Knight, G. P., Umaña-Taylor, A. J., Rivas-Drake, D., Lee, R. M., \& Ethnic/Racial Identity Study Group. (in press). Methodological issues in ethnic and racial identity research with ethnic minority populations: Theoretical precision, measurement issues, and research designs. Child Development.

Sellers, R. M., Smith, M. A., Shelton, J. N., Rowley, S. A. J., \& Chavous, T. M. (1998). Multidimensional model of racial identity: A reconceptualization of African American racial identity. Personality and Social Psychology Review, 2(1), 18-39.

Smith, T. B., \& Silva, L. (2011). Ethnic identity and personal well-being of people of color: a meta-analysis. Journal of Counseling Psychology, 58, 42-60.

Syed, M. (2010a). Developing an integrated self: Academic and ethnic identities among ethnically-diverse college students. Developmental Psychology, 46(6), 1590-1604.

Syed, M. (2010b). Memorable everyday events in college: Narratives of the intersection of ethnicity and academia. Journal of Diversity in Higher Education, 3(1), 56-69.

Syed, M. (2012a). College students' storytelling of ethnicity-related events in the academic domain. Journal of Adolescent Research, 27(2), 203-230.

Syed, M. (2012b). The past, present, and future of Eriksonian identity research: Introduction to the Special Issue. Identity: An International Journal of Theory and Research, 12(1), 1-7.

Syed, M. (2013). Assessment of ethnic identity and acculturation. In K. Geisinger (Ed.), APA handbook of testing and assessment in psychology (pp. 393-405). Washington DC: American Psychological Association.

Syed, M., \& Azmitia, M. (2008). A narrative approach to ethnic identity in emerging adulthood: Bringing life to the identity status model. Developmental Psychology, 44(4), 1012-1027.

Syed, M., \& Azmitia, M. (2009). Longitudinal trajectories of ethnic identity during the college years. Journal of Research on Adolescence, 19(4), 601-624.

Syed, M., \& Azmitia, M. (2010). Narrative and ethnic identity exploration: A longitudinal account of emerging adults' ethnicity-related experiences. Developmental Psychology, 46(1), 208-219.

Syed, M., Azmitia, M., \& Phinney, J. S. (2007). Stability and change in ethnic identity among Latino emerging adults in two contexts. Identity: An International Journal of Theory and Research, 7(2), 155-178.

Syed, M., \& Hu., A. (2013). Diverging pathways of socialization from peers and parents to ethnic identity. Manuscript in preparation. 
Syed, M., \& Juan, M. J. D. (2012). Discrimination and psychological distress: Examining the moderating role of social context in a nationally representative sample of Asian American adults. Asian American Journal of Psychology, 3(2), 104-120.

Syed, M., Walker, L. H. M., Lee, R. M., Umaña-Taylor, A. J., Zamboanga, B. L., Schwartz, S. J., Armenta, B. E., \& Huynh, Q.-L. (2013). A two-factor model of ethnic identity exploration: Implications for identity coherence and well-being. Cultural Diversity and Ethnic Minority Psychology, 19(2), 143-154.

Tajfel, H., \& Turner, J. C. (1986). The social identity theory of intergroup behavior. In S. Worchel \& W. G. Austin (Eds.), Psychology of intergroup relations, (pp. 7-24). Chicago: Nelson-Hall.

Taylor, J. M., Gilligan, C., \& Sullivan, A. M. (1996). Missing voices, changing meanings: Developing a voice-centered, relational method and creating an interpretative community. In S. Wilkinson (Ed.), Feminist social psychologies: International perspectives. Buckingham, UK: Open University Press.

Thorne, A. (2000). Personal memory telling and personality development. Personality and Social Psychology Review, 4(1), 45-56.

Thorne, A., \& McLean, K. C. (2003). Telling traumatic events in adolescence: A study of master narrative positioning. In R. Fivush \& C Haden (Eds.), Autobiographical memory and the construction of a narrative self: Developmental and cultural perspectives, (pp. 169-185). Mahwah, NJ: Erlbaum.

Umaña-Taylor, A. J. (2001). Ethnic identity development among Mexican-origin Latino adolescents living in the U.S. Unpublished doctoral dissertation, University of Missouri, Columbia.

Umaña-Taylor, A. J. (2004). Ethnic identity and self-esteem: examining the role of social context. Journal of Adolescence, 27, 139-146.

Umaña-Taylor, A. J., Quintana, S. M., Lee, R. M., Cross, W. E., Rivas-Drake, D., Schwartz, S. J., Syed, M., Yip, T., Seaton, E., \& Ethnic/Racial Identity Study Group. (in press). Ethnic and racial identity revisited: An integrated conceptualization. Child Development.

Umaña-Taylor, A. J., Yazedjian, A. \& Bámaca-Gómez, M. Y. (2004). Developing the Ethnic Identity Scale using Eriksonian and social identity perspectives. Identity: An International Journal of Theory and Research, 4, 9-38.

Vo-Jutabha, E. D., Dinh, K. H., McHale, J. P., \& Valsiner, J. (2009). A qualitative analysis of Vietnamese adolescent identity exploration within and outside an ethnic enclave. Journal of Youth and Adolescence, 38, 672-690.

Walker, L. H. M., \& Syed, M. (2011, October). Emerging adults' stories of their ethnicityrelated experiences: A narrative analysis of cognitive, affective, and behavioral components. Paper presented at the $5^{\text {th }}$ Conference on Emerging Adulthood, Providence, RI.

Wang, Q. (2008). Being American, being Asian: The bicultural self and autobiographical memory in Asian Americans. Cognition, 107, 743-751.

Way, N., Santos, C., Niwa, E. Y., \& Kim-Gervey, C. (2008). To be or not to be: An exploration of ethnic identity development in context. In M. Azmitia, M. Syed, \& K. Radmacher (Eds.), New directions for child and adolescent development: Intersections between personal and social identity, 120, 61-79. San Francisco: Jossey-Bass.

Weisskirch, R. S., Zamboanga, B. L., Ravert, R. D., Whitbourne, S. K., Park, I. J., Lee, R. M., \& Schwartz, S. J. (2013). An introduction to the composition of the Multi-Site University 
Study of Identity and Culture (MUSIC): A collaborative approach to research and mentorship. Cultural Diversity and Ethnic Minority Psychology, 19(2), 123-130.

Wohlwill, J. F. (1973). The study of behavioral development. New York: Academic Press.

Yip, T. (2005). Sources of situational variation in ethnic identity and psychological well-being: A palm pilot study of Chinese American students. Personality and Social Psychology Bulletin, 31(12), 1603-1616.

Yip, T., Gee, G. C., \& Takeuchi, D. T. (2008). Racial discrimination and psychological distress: The impact of ethnic identity and age among immigrant and United States-born Asian adults. Developmental Psychology, 44(3), 787-800.

Yip, T., Seaton, E. K., \& Sellers, R. M. (2010). African American racial identity across the lifespan: Identity status, identity content, and depressive symptoms. Child Development, 77, 1504-1517.

Yoo, H. C., \& Lee, R. M. (2008). Does ethnic identity buffer or exacerbate the effects of frequent racial discrimination on situational well-being of Asian Americans? Journal of Counseling Psychology, 55(1), 63-74. 


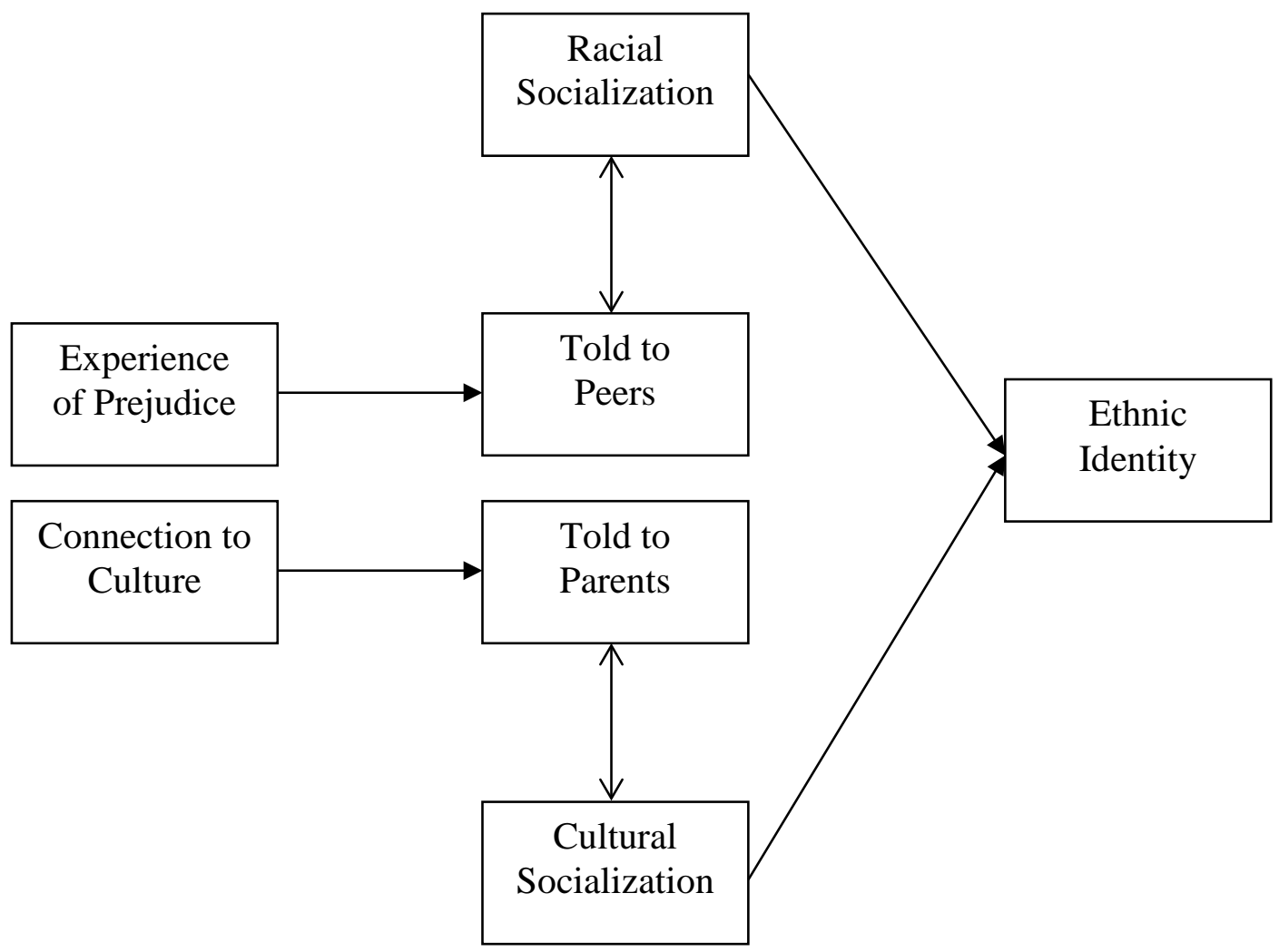

Figure 1. Model showing peer and parent socialization patterns to ethnic identity 